\title{
LA LEY GENERAL DE EDUCACIÓN Y LA PEDAGOGÍA. REENCUENTRO Y SEÑAL
}

\author{
The General Education Act and the Pedagogy. \\ Recovering and sign.
}

\section{Alejandro Mayordomo Pérez}

Fecha de recepción: 26/10/2020 • Fecha de aceptación: 01/02/2021

Resumen. El artículo presenta una amplia perspectiva histórica sobre las consideraciones pedagógicas que caracterizan y se proponen en la reforma de la educación básica en la España de 1970. Para ello el texto desarrolla una descripción e interpretación de documentos legislativos, políticos y técnicos; y precisa los contextos, las innovaciones, las contradicciones y las insuficiencias de la Ley Villar Palasí. Básicamente el autor trata de identificar y mostrar las características que presenta la racionalidad científica o modelo técnico de la reforma, la falta de correspondencia o conexión entre la pedagogía defendida, el contexto social y cultural, y las políticas concretas que debían activarse para cumplir sus objetivos. Finalmente, hay que señalar que este trabajo intenta clarificar el sentido de la Ley General de Educación en la historia educativa de España.

Palabras clave: Ley General de Educación (1970); política educativa española; reformas educativas; modelo pedagógico; ruptura y continuidad en las políticas educativas; franquismo y educación.

Abstract. This paper undertakes a historical overview of the pedagogical considerations and references that characterize the basic educational reform in Spain in 1970. To do so, the text offers a description and interpretation of technical, political and legal documentation. Additionally, it clarifies the contexts, orientations, innovations and shortcomings of the legislation, known as the Villar Palasi law. Basically, the author attempts to demonstrate the characteristics of the scientific rationality or technical model of the law and its reform. The article also addresses the lack of

\footnotetext{
$\alpha$ Facultad de Filosofía y Ciencias de la Educación. Departamento de Educación Comparada e Historia de la Educación. Avenida de Blasco Ibáñez 30, 46020 Valencia, España. Alejandro.Mayordomo@uv.es (iD https://orcid. org/0000-0002-0029-7057
}

Cómo citar este artículo: Mayordomo Pérez, Alejandro. «La Ley General de Educación y la pedagogía. Reencuentro y señal». Historia y Memoria de la Educación 14 (2021): 69-110 
agreement between the pedagogy being defended, the social and cultural context, and the specific policies that needed to be introduced in order for the reform to achieve its objectives. And finally, this work tries to clarify the significance of this General Education Act in the educational history of Spain.

Keywords: General Education Act (1970); Spanish education policy; educational reforms; pedagogical discourses; rupture and continuity in educational politics; francoism and education.

La Ley General de Educación (LGE) fue un hito en la larga historia de esperanzas y fracasos que configuran la construcción del sistema educativo español. Aquel importante documento legal, sus problemáticas potencialidades en el concreto contexto del final del franquismo, y su capacidad para posibilitar después -durante 20 años- modificaciones y cambios, tuvieron un significativo papel -como afirmación, como reto, y como anuncio- en la resolución de ese persistente proyecto. Ha sido, y es, un referente.

Sin duda puede situarse de modo relevante en aquel reiterado proceso reformador, que en nuestra historia educativa ha estado cargado y acompañado de ideologización, inestabilidad política, insuficiencia económica, y repleto de singulares retóricas, deficiencias normativas, incumplimientos, y retrasos. Una discontinuidad más.

Quizás convenga recordar, en principio, el doble sentido sociopolítico y pedagógico de la reforma que anima: por una parte, como el intento de canalizar una propuesta de transformación social, de modernización dentro de la continuidad, que avanzara en la necesidad de hacer partícipe de la educación a toda la población española; y, además, como un propósito de elevación de la cultura individual y social. Cambios sociales, nuevas aspiraciones y reivindicaciones, diferentes y urgentes necesidades, distintos valores emergentes relacionados con lo económico, el desarrollo, la eficiencia, la rentabilidad de la educación como inversión; son, todos ellos, factores concurrentes que generan críticas a la situación y plantean rectificaciones a desarrollar. Se postulaba una reforma global de nuestro sistema educativo.

De esa manera se defienden algunos objetivos primordiales: democratizar, implementar el derecho a la educación, promover la igualdad de oportunidades, perfilar la educación como servicio público fundamental. 
Esta última cuestión es considerada, aunque cautelosamente, en el debate que dictamina el proyecto de ley, partiendo de una precisión planteada por Fernando Suárez González. ${ }^{1}$

$\mathrm{Y}$ es que aparece la necesidad de interpretar «debidamente» el tema, en razón del peligro -se llega a decir- del monopolio escolar. Monseñor Cantero Cuadrado, en su intervención como procurador, concibe ese concepto desde un punto de vista que califica como filosófico; para él la educación más que un servicio público, es una función social: «He votado que era la educación un servicio público fundamental. Es evidente. Ahora bien, que si se hace es siempre que esté por encima del servicio público la función social». Iglesia, Estado y familias son sus más eficientes responsables, opina el arzobispo de Zaragoza. ${ }^{2}$ La ponencia se suma a la posición de Cantero; interpreta que se trata de un servicio público fundamental, el Estado debe tener la obligación, la responsabilidad económica, el compromiso, de que este servicio llegue a todos; ahora bien, la forma de hacerlo es otra cosa: «lo cumple de una manera directa, a través de sus propios centros, y lo cumple por medio de instituciones públicas o privadas que tienen también sus centros, los cuales conciertan con el Estado».

Cuando Villar abre las sesiones de la Comisión de Educación y Ciencia, señala de forma muy clara que la política educativa que se propone es ante todo una «política social» que haga frente a «intolerables situaciones de privilegio». Él mismo presentando, meses después, el proyecto

\footnotetext{
1 «[...] al hablar de la educación como servicio público fundamental hemos, utilizado un "flatus vocis"; hemos dicho algo no en el sentido técnico que tiene el servicio público en el ordenamiento jurídico español, sino en un sentido distinto, me atrevería a decir literario, del concepto riguroso del servicio público. El servicio público -la Ponencia lo sabe muy bien- es, para la doctrina, lo que justifica la existencia del Estado mismo; de tal manera que la actividad de que se trata queda asumida por el Estado como propia del mismo. A partir de ese momento, la actividad no se puede ejercer más que por delegación del' Estado, pero naturalmente ello no conduce a que el Estado tenga que hacerse cargo de la gestión de todos los servicios públicos, porque puede concederla a otras instituciones. [...] Y como la educación es un servicio público fundamental, si se hace, en rigor, repito, se hace por concesión del Estado. Y a mí eso me parece una aberración; me parece absolutamente incompatible con la afirmación de que hay centros pertenecientes otras instituciones. Y como quizá este argumento o este razonamiento conduciría a un callejón sin salida, sería conveniente precisar de alguna manera que aquella afirmación del servicio público fundamental no está entendida en el sentido que en nuestras leyes tienen los servicios públicos». Diario de Sesiones de las Cortes Españolas (DSCE), 41 (6-V-1970), 18.
}

2 DSCE, 41 (6-V-1970), 22-25. 
de ley recalca el sentido de integración social de la misma, buscando eliminar «toda barrera discriminatoria». ${ }^{3}$

Y, además de esa consecución social, se pretende que el funcionamiento del sistema educativo quede tajantemente, "supeditado» a los «imperativos» y la «evolución» de la «técnica pedagógica». Aquí observaremos esa dimensión pedagógica, poniendo de relieve los principios y marcos establecidos para la mejor cualificación y resultado de la formación: la renovación y racionalización pedagógica, al servicio de la eficacia y la calidad de nuestro sistema educativo. Recordemos una frase de Villar, en su parlamento ante la Comisión: «enseñamos muchas cosas, pero no a pensar ni a vivir».

Eso requería la contribución de la pedagogía a fijar nuevos fines y diferentes medios. Ahora bien, ya debemos adelantar que esa posición pedagógica va a conformarse olvidando que las prácticas educativas no son términos neutrales, puramente descriptivos... olvidando que, como señala Popkewitz, la política educativa y curricular contiene cuestiones de producción social, valores sociales, relaciones de poder y prácticas culturales. ${ }^{4}$

\section{DEFINICIONES Y PROPUESTAS}

El enfoque pedagógico de la ley tiene un espacio relevante de desarrollo en la llamada Educación General Básica (EGB). En este punto, al que trataré de prestar mayor atención, los principios y objetivos adoptados pueden resumirse en los siguientes aspectos:

a) Mejorar la calidad y los resultados del sistema educativo, algo que suponía hacerlo más justo y eficaz, homogéneo, flexible e interrelacionado.

b) Establecer una escuela unificada de 6-14 años, que garantizara «oportunidades educativas» a la totalidad de la población. Se trataba de construir una oferta de escolarización obligatoria dividida en dos etapas, la primera de cinco cursos, y la segunda de tres.

\footnotetext{
${ }^{3}$ DSCE, 19 (1-IV-1970), 2-12.

${ }_{4}^{4}$ Thomas S. Popkewitz, Sociología política de las reformas educativas. El poder-saber en la enseñanza, la formación del profesorado y la investigación (Madrid-La Coruña: Morata-Fundación Paideia, 1994).
} 
c) Implementar la EGB como espacio de formación integral que debería desplegar un tratamiento educativo presidido por principios y estrategias metodológicas y organizacionales actualizadas; muy próximas a la educación personalizada.

d) Combinar la globalización de materias con una moderada diversificación, estructurando los contenidos formativos en grandes áreas de aprendizaje, que evitasen la fragmentación en asignaturas.

e) Desarrollar métodos innovadores, que fomentaran la originalidad, la expresión y la creatividad, el trabajo cooperativo; propiciando la realización de una enseñanza viva, activa y participativa.

f) Conseguir el progreso del alumnado en la adquisición y disponibilidad funcional de técnicas y hábitos de aprendizaje.

g) Incluir en los objetivos educativos el desarrollo de las capacidades de imaginación, observación y reflexión, y de aptitudes para la convivencia.

h) Fomentar lo que se denomina como un «estilo propio» de cada centro, y que consecuentemente requerirá la prestación de apoyo y estímulos a sus iniciativas, ensayos y realizaciones positivas.

i) Incorporar al sistema los oportunos servicios de orientación y tutorización escolar.

j) Preparar una revisión completa del contenido de la educación, mediante una renovación general y actualizada de programas y orientaciones.

k) Establecer una cuidadosa evaluación del rendimiento escolar; evaluación que sería un procedimiento más de orientación, «integrante de la actividad educativa»; y que debería efectuarse con la estimación global del progreso y resultados en la primera etapa, y con pruebas flexibles de promoción y la intervención del equipo docente, en la segunda. ${ }^{5}$

l) Crear los oportunos mecanismos institucionales dedicados a la formación permanente del profesorado en el ámbito pedagógico,

5 O.M. 16-XI-1970 (BOE 25-XI-1970); Resolución 17-XI-1970 (BOE 25-XI-1970); Resolución 25-XI1970 (BOE 3-XII-1970). 
algo que se presenta repetidamente como garantía esencial del avance de la reforma.

$\mathrm{Al}$ objeto de poner en funcionamiento ese nuevo modelo se establecieron unas Orientaciones Pedagógicas ${ }^{6}$ para los planes y programas de estudio en la EGB; unas pautas que se entienden como «necesariamente comunes», aunque "diversamente alcanzables». Cuando se prorrogan, en 1971, se las califica como un instrumento ágil y flexible. ${ }^{7}$

Hay que advertir, en primer lugar, que tales orientaciones no se presentan como prescripciones rígidas, sino más bien como directrices y sugerencias de carácter experimental. Quieren ofrecer un detallado repertorio de definiciones de posición y propuestas de actuación; pero, sin embargo, entran con frecuencia en aspectos bien concretos dirigidos a la renovación de las instituciones escolares y la mejora del rendimiento, es decir, a una actuación sobre la efectividad. Sin duda, la significación básica de algunos de esos puntos merece su explicitación.

Por ejemplo: en cuanto a los objetivos, para la primera etapa se subordina la información a la formación y al desarrollo de la personalidad de los alumnos. En ese sentido se pretende primar los referidos a estimular la integración social, las facultades creadoras, los intereses científico-culturales; además hay una llamada a activar oportunidades didácticas para que el alumno se exprese en las diversas áreas del lenguaje y pueda llegar a nociones generales que cimienten la continuidad de su formación. Ya en la segunda etapa el objetivo es ir alcanzando un mayor nivel y desarrollo en la adquisición y sistematización de los conocimientos. Los objetivos, como comportamientos o modos de actividad que puedan ser evaluados, se presentan en diversos niveles: general, específico, de contenidos, de conductas formales, y operacionales.

Las áreas fundamentales de aprendizaje quedan agrupadas en los ámbitos de la «expresión» y la «experiencia»: el lenguaje verbal, considerado como instrumento básico que garantiza logro y progreso en todas las demás áreas, y que requiere un especial cuidado de aspectos como la capacidad de expresión ordenada y de comprensión, la actitud positiva hacia la lectura, la habilidad de leer, hablar y escribir comprensivamente

6 O.M. 2-XII-1970 (BOE 8-XII-1970).

7 O.M. 6-VIII.1971 (BOE 24-VIII-1970). 
en una lengua extranjera; el lenguaje matemático, dirigido a la matematización de problemas, creación de sistemas formales, utilización de esos sistema, y su interpretación; la expresión plástica, como recurso promotor de espontaneidad, creatividad, imaginación y sensibilidad; la expresión dinámica, para la educación del movimiento, el ritmo, la expresión corporal, juegos, deporte y gimnasia; la experiencia social y cultural, conocimiento histórico, geográfico, socioeconómico, político, que promueva, más que la memorización, la formación de actitudes y criterios, el ejercicio del análisis, la síntesis, la interpretación; las ciencias de la Naturaleza, para el conocimiento del medio físico, y el desarrollo de la observación, la experimentación y el pensamiento crítico y científico; y, en fin, la formación religiosa, con un matiz en sus objetivos que cabe resaltar, el interés por ayudar a «redescubrir» la fe en un mundo de progreso y cambio.

Después las orientaciones establecen unos niveles de contenido, formulándose los objetivos específicos que se han de ir alcanzando gradualmente, y que son considerados como meta y medio en el proceso educativo. En este aspecto se indica la importancia de cuidar la oportuna conexión entre la primera y segunda etapa de EGB y con el posterior Bachillerato. También es destacable que la formulación de los niveles se haga en términos de objetivos operacionales, una opción que responde al deseo de que los profesores puedan controlar y revisar las distintas unidades formadas por uno o más de dichos objetivos, de manera que la observación de comportamientos y la evaluación continuada fueran los instrumentos para mejorar el proceso educativo en general.

Una referencia a la evaluación del rendimiento educativo que ya había quedado definida como parte integrante, sistemática y sustancial de la actividad educativa, que descubre aptitudes e interés, que ayuda a la orientación, la recuperación, la adecuación de contenidos, la colaboración con las familias, etc. Las Orientaciones entran, aquí, en bastantes detalles: exploración psicológica inicial del alumnado, consejo de evaluación, observación de hábitos y actitudes, atención a los comportamientos, al aprovechamiento, a la madurez, y a la integración social. Cuando se plantea ese trabajo y servicios, sorprenden los niveles de importancia y exigencia que se les atribuye como tarea continuada de diagnóstico y tratamiento psicopedagógico del escolar; más necesaria todavía en épocas de transición y cambio, es decir, al ingresar en el centro y 
al término de cada una de las dos etapas. Claramente relacionado con ello, y como recurso para lograr cohesión y eficacia en el equipo docente, la ley impulsa el establecimiento de un sistema tutorial. Aunque todos los profesores deben ser tutores, en la segunda etapa se instituye la figura de un tutor para cada grupo de alumnos, cuya función es establecer los contactos con los padres, con el departamento de orientación, equipo directivo y personal docente.

Las Orientaciones abordan, por otro lado, el concepto de organización escolar; apuntan que esta ha de ser expresión de la teoría educativa adoptada, y que en su calidad de medio e instrumento se basa -como se dice explícitamente-, en los principios de la educación personalizada. La organización, se afirma, será una estructura dinámica, tendrá que ser funcional, flexible y eficaz Eso sí, reflejará «las ideas vigentes sobre la sociedad, sobre el hombre que se educa, sobre la naturaleza del proceso de aprendizaje y sobre la función que se asigna a la escuela dentro de la comunidad». Ese concepto y tejido organizativo se revela al plantearse dos demandas básicas: el cuidado de las relaciones humanas dentro de la comunidad educativa, y el impulso al desarrollo de iniciativas y la capacidad creadora de sus integrantes. Y para ello se abren tres interesantes perspectivas más: la iniciativa de los centros, la creación de un «estilo propio» desde una "libertad de acción responsable»; el trabajo en equipo e integración del centro en su medio; y la racionalización de los espacios y el tiempo escolar.

Otro aspecto destacado es la agrupación de los alumnos, que deberá ser flexible, según la naturaleza de la actividad de que se trate; y además ha de estar en armonía con lo que exigen las diversas situaciones de aprendizaje, y permitir distintos tipos de trabajo escolar (individual, pequeño grupo, grupo medio o grande) y diversas ocasiones de experiencias asociativas (mayores y pequeños, brillantes y medianos, de ambientes sociales diferentes, etc.).

Y todavía hay que aludir a un tema convertido en todo un descriptor de la reforma para aquellos que aún hoy proclaman: "yo fui a la EGB». Me refiero a «las fichas» (directivas o de orientación, de contenido o información, de recuperación, de desarrollo, y de control o autoevaluación). Sin duda, fueron un material y recurso didáctico central. Se elogiaba su contribución al desarrollo de la actividad individualizada; así 
como su valor para, de manera personalizada, orientar y graduar el aprendizaje y fomentar hábitos de estudio.

Estas son, en resumen, muestras sustanciales de la concepción curricular de la ley. Un proyecto dirigido esencialmente a psicologizar el aprendizaje y tecnificar la enseñanza; desde tal posición el currículum se centraba en una programación determinada desde los objetivos conductuales predefinidos; y en un proyecto que se situaba así en la perspectiva del taylorismo educativo, con especial cuidado de la ejecución de operaciones, del refuerzo, del control, del rendimiento.

Pero, con todo, el texto de la LGE incorpora un conjunto importante de conceptos/opciones para la renovación: el aprendizaje como proceso individual, la madurez preparatoria, el redescubrimiento personal del saber, las diferencias y gradaciones en el trabajo didáctico, la función de globalización, el activismo funcional, las necesidades vitales como motivación, etc.

Veamos, ahora, el asunto desde otra perspectiva. La norma legislativa apuntaba, un apreciable discurso pedagógico, pero tan importante y extensa alusión a cuestiones de fundamentación técnica, no tuvo su correlato en el debate político que se desarrolló en las Cortes franquistas. El foco, en ese lugar, se ponía significativamente sobre otros temas.

Allí se reitera, se justifica -con palabras del ministro- que el texto legal responde a caracteres y problemas específicos de nuestro país, que no hay nada «extranjerizante en forma o fondo"; y se matiza que el proyecto combina el deseo de avance con la insistencia en la continuidad, la afirmación de la innovación con la llamada a las formas paulatinas, la necesaria prudencia, las cautelas. Recordemos, si acaso, la frecuencia con la que el Régimen se escudaba en el peligro del llamado ejercicio «abusivo» de las libertades. Esas fueron otras materias a vigilar con la finalidad de asegurar la ortodoxia o corrección política de los nuevos aires pedagógicos. ${ }^{8}$ Esa es una primera significación a tener en cuenta.

En las sesiones parlamentarias aparecen tratadas variadas cuestiones como la cualificación profesional de los trabajadores, la educación

8 DSCE (9-VII-1970), 29-35. 
de adultos, la educación especial, la libertad de enseñanza. ${ }^{9}$ Pero, aunque con brevedad, atendiendo a los límites del artículo, hay otras que merecen, especialmente, ser recogidas aquí. Es el caso del tema de la coeducación, reclamado en diversas intervenciones. ${ }^{10}$ Por ejemplo, el procurador Beltrán Rojo pretende que se ponga de relieve la admisión del sistema coeducativo por razones psicológicas y sociológicas, y en aras de integración y convivencia; y la procuradora Landaburu González pide que se cite expresamente el principio de no discriminación por razón de sexo. En este asunto la Ponencia considera innecesario poner énfasis en cuanto a la coeducación, porque si la ley no lo impide no hay razón para imponerla, y porque como la ley no contempla aquella citada discriminación, ciertamente no es necesario recogerla. Las posiciones, ciertamente, se contraponen: el Rector de la Universidad de Zaragoza (Casas Peláez) recela de la imposición de la coeducación y, aunque no los define, de sus posibles peligros o inconvenientes, sobre todo para las mujeres; y Labadie Otermin pide el reconocimiento del derecho a la coeducación (con carácter obligatorio en centros estatales y discrecional en los privados), así como en incorporar la «educación sexual» en los nuevos planes de estudio, salvando, no obstante, la existencia de las clásicas enseñanzas propias del alumnado femenino.

Desde la representación ministerial se establece la posición oficial. El subsecretario, Díez Hochleitner, afirma que: «Todo lo que se dice de los hombres se dice igualmente de las mujeres a la hora de legislar en materia educativa»; añadiendo enseguida que la educación sexual es un tema que se está sacando de quicio, que no debe ser una asignatura, sino en cualquier caso una formación transversal desde la biología, la convivencia o la religión. En materia de coeducación, concluye, «se pueden cometer muchos errores», siendo necesario actuar con gradualidad, de forma evolutiva y flexible, cuando los padres quieran, o en diferentes lugares que sean aconsejables. Y la directora general de Enseñanza Media, Ángeles Galino, coincide en resaltar la potencialidad que la ley ofrece en ese punto; la ley, dice, dejará anuladas las prescripciones legales que impiden la coeducación y, por lo tanto, es un "paso adelante». Su criterio es que "pueden y deben permitirse, de manera paulatina, las

\footnotetext{
${ }_{9}$ DSCE (5-V-1970), apéndice 39, 56-71.

${ }_{10}$ DSCE, 27 (14-IV-1970), 34-55.
} 
situaciones que resulten aconsejables»; y desde esa posición lanza un mensaje: «No nos asustemos, porque se puede hacer con todas las garantías que la moral, la pedagogía y las normas jurídicas requieran».

Otro tema que suscita controversia es el de las llamadas lenguas «vernáculas». Son varios procuradores los que defienden una legislación favorable a su incorporación en la enseñanza. Así lo hacen Mir Martí y Viola Sauret, en la sesión del 2 de abril; o Rosón Pérez, cuando días después y tratándose de los artículos dedicados a la educación prees colar, pide que al referirse a las actividades del lenguaje se diga expresamente actividades en «lenguajes nacional y vernáculo», ya que valora el empleo de la lengua materna como medio valioso de educación, basado en unos principios pedagógicos de vigencia universal, en principios científicos experimentados. ${ }^{11}$

En este asunto destaca la intervención de Filgueira Valverde; el galleguista reclama con fuerza que el tema quede planteado en el terreno de la pedagogía, y afirma que el bilingüismo no es ninguna anomalía, sino más bien es una riqueza, un bien. Filgueira revisa algunas posiciones históricas y se remonta al padre Sarmiento, recordando que la adquisición del lenguaje es un choque de lo nativo con lo adquirido, por lo que es recomendable la lengua nativa como lengua vehicular. Y Escudero Rueda entiende que «lenguas vernáculas» son las nativas o maternas, que «para mí -dice- tienen el sentido de nacionales» en cuanto se integran todas en la «hispanidad». Sus consideraciones llegan a contemplar dos escenarios: en uno, el caso de las zonas con predominio de la lengua vernácula, todas las actividades serían en esa lengua, pero introduciendo elementos del lenguaje oficial; y en zonas de dominio del castellano, las actividades se harían en castellano, aunque introduciendo poco a poco el lenguaje vernáculo. ${ }^{12}$

Otra componente, que conviene citar, aparece cuando se analiza en la Comisión el artículo 19, y se habla sobre las pruebas flexibles de promoción o las enseñanzas complementarias de recuperación, así como la promoción automática de curso. Este último tema es muy discutido por algunos procuradores. Reus Cid advierte sobre una posible «picaresca»;

\footnotetext{
11 DSCE, 30 (17-IV-1970), 4.

12 DSCE, 30 (17-IV-1970), 6-11.
} 
Puig Maestro-Amado considera ese modelo «entorpecedor» y propugna que la propuesta se modifique en el sentido de que «no pasarán sin haber aprobado»; Lostau Román cree que es «perjudicial». Otros proponen diferentes fórmulas, como Mayor Zaragoza, que postula la expresión "podrá pasar», o Martínez Estenaga que sugiere la de «quedarán condicionados en su pase al siguiente (curso) a la información complementaria y suficiente de recuperación», o la demanda hecha por Pilar Primo de Rivera, en el sentido de que lo dispuesto fuera que el alumnado pudiera, o debiera, repetir a juicio del profesor. ${ }^{13}$

Y en relación con lo que acabamos de anotar, otro asunto suscita reacciones contrarias: el establecimiento de la doble titulación (graduado escolar, certificado de escolaridad), que debía acreditar a quienes cursaran la EGB. para poder acceder o bien a la Formación Profesional o bien al Bachillerato. A algunos, como principalmente Sanz Orrio, les parece improcedente por su efecto de señalar una distinción entre «listos que estudian carreras y tontos que se dedican a oficios»; no le parece «social» dicha discriminación de títulos, que, insiste en otra ocasión, crea como una "patente de torpes» para quienes se han de dirigir a la Formación Profesional. Lo deja extraordinariamente claro: «¿Qué necesidad tenemos de señalar con un estigma a muchos muchachos que, brillantes o no, tal vez sean unos magníficos trabajadores, que para mí tiene tanto mérito como cualquier otra actividad?». ${ }^{14}$

En el mismo sentido, Labadie Otermín ${ }^{15}$ manifiesta, de forma contundente, que esa medida diferenciadora que plantea el proyecto encierra una gravedad extraordinaria, porque sin estimar la variedad ritmos o modos en el aprendizaje, se distingue entre «listo y no listos», entre «capacitados y no capacitados»: «al muchacho que hemos suspendido, al que no le hemos concedido el pase al Bachillerato superior, le damos un título que le consagra para siempre de tonto, de incapaz». Es inadmisible desde el criterio técnico-pedagógico e injusto desde el punto de vista humano y social, añade, que estigmaticemos a esos muchachos.

\footnotetext{
13 DSCE, 31 (21-IV-1970), 17-37.

14 DSCE, 31 (21-IV-1970), 39-40.

${ }^{15}$ DSCE, 31 (21-IV-1970), 33-35.
} 
Anotemos, también que las procuradoras Plaza, Ballenina, Primo de Rivera y Loring intentan cambiar la denominación de «enseñanzas del hogar» por la de «ciencias domésticas»; un ámbito formativo que consideran como parte de una educación integral, tanto para varones como para mujeres: no se trata -manifiestan- de «laborcitas», sino de algo más científico. ${ }^{16}$

Y acabemos este apartado señalando que el Rector de la Universidad de Valencia, Barcia Goyanes, introduce en el debate ciertas especificaciones sobre las necesidades educativas especiales. Una tiene que ver con lo que califica como «tratamiento de los inadaptados» tanto al medio familiar como al escolar, niños difícilmente educables; son áreas que, según él, reclaman una atención para que el profesorado reciba ayuda y asesoría, y por ello pide la creación de centros de «orientación terapéutica». Barcia manifiesta igualmente el tema de los superdotados, como algo que queda enmascarado de alguna forma y genera que tales niños puedan aparecer como deficientes "porque, con una capacidad de comprensión muy superior a la de los muchachos que le rodean, a los tres minutos está de vuelta de lo que el profesor está explicando, y se aburre soberanamente en la clase».17

\section{CONTEXTOS}

Es obvio que, en las concepciones que sustenta LGE y en la normativa pedagógica consecuente, ni se genera ni se construye ex novo; hay en ellas regresos que restituyen, elecciones que significan preferencias, contextos que entretejen. Son relaciones que ayudan a clarificar el sentido y momento en que se promulga.

Comencemos considerando el concepto capital humano; y eso significa incorporar una categoría fundamentalmente económica. Ese «capital» es considerado como un insumo estratégico a causa de las externalidades (consecuencias o influencias) positivas que transmite. Se relaciona con la necesidad de invertir en conocimiento y cualificación, un valor intangible para ir mejorando así la calidad de la mano de obra y enfocando la educación, también, como productora de capacidad de trabajo. Es, claro, uno de los determinantes de la productividad, y de ahí que se estimaran los importantes retornos de aquella inversión.

\footnotetext{
${ }^{16}$ DSCE, 30 (17-IV-1970), 24-25.

${ }_{17}$ DSCE (5-V-1970), 60-61 y 66.
} 
Recordaremos que la OCDE insistió, tras la II Guerra Mundial, en el interés por el crecimiento económico sostenible y por la educación necesaria para ello, y que la década de los sesenta subrayó la importancia del factor educación para el desarrollo económico. Theodor Schultz señala, en 1961, que invirtiendo en sí mismos los seres humanos aumentan sus posibilidades; procedía, pues, invertir en la gente para aumentar la calidad de la gente. Y Gary Becker resalta esa potencialidad de la educación, junto a la experiencia y el entrenamiento, como inversión en stock inmaterial.

En ese aspecto, y en España, el I Plan de Desarrollo (1964-1967) incluye el acceso a la enseñanza primaria como instrumento importante de la política de promoción social y económica, siguiendo lo que ya nos había señalado el Informe del Banco Mundial (1962), cuando señalaba que una buena educación general era indispensable para que los productores españoles adquirieran la pericia de sus competidores en el mundo. ${ }^{18}$ Por eso se amplía aquí la escolaridad obligatoria hasta los 14 años: por la necesidad de constituir un supuesto indispensable para la solución de nuestros problemas económicos y sociales. ${ }^{19}$

Tal política defiende teóricamente un desarrollo económico como proceso indivisible que comporte igualmente la prevalencia en el mismo de objetivos humanos y sociales. Y quedaba señalado, de esa forma, que la consecución de un adecuado nivel técnico y humano requería la igualdad de oportunidades para el acceso a los medios educativos. Otra cosa es, ciertamente, que la planificación y programación fuera desarrollada, a continuación, con la adecuada racionalidad.

Después, en las vísperas de la preparación y promulgación de la ley, el II Plan remarcaba que todos los españoles debían conseguir el derecho y deber de recibir educación hasta el máximo de sus posibilidades intelectuales y profesionales; era una prioridad, se reconocía otra vez, la enseñanza primaria, y el emprender las oportunas reformas del sistema educativo. ${ }^{20}$ Posteriormente el III Plan no añadió refuerzos a este propósito. ${ }^{21}$

\footnotetext{
${ }^{18}$ Ley de 28-XII-1963, BOE 30-XII-1963.

19 Ley de 29-IV-1964, BOE 4-V-1964.

${ }^{20}$ Ley de 11-II-1969, BOE 12-XII-1969.

${ }^{21}$ Ley de 10-V-1972, BOE 11-V-1972.
} 
El referente estaba claro. Podemos constatarlo en 1967, por ejemplo, cuando Cotorruelo Sendagorta, economista y subcomisario del Plan de Desarrollo, reconoce esa tarea de formar capital humano como factor de desarrollo económico; postula la conexión entre inversión en educación y desarrollo económico, refiriéndose a los estudios sobre la rentabilidad individual y global de la educación de autores como Becker, Schultz, Denison, o Solow. La dirección queda bien clara: educación primaria universal y acceso de todos los que tengan aptitudes a la segunda enseñanza. Muy poco después, las Bases para una nueva política educativa explicitaban suficientemente este enfoque, resaltando algunos temas importantes: el deseo de mejorar el nivel de vida, la aspiración al desarrollo socioeconómico, la demanda de educación como medio de movilidad socioeconómica y cultural, la necesidad de que el sistema educativo se relacionase adecuadamente con la estructura ocupacional.

En esas circunstancias, con el predominio del vínculo entre educación y desarrollismo económico, el desarrollo de la personalidad se asociaba a la necesaria igualación de oportunidades para la promoción individual, y conducía a un crecimiento del ingreso per capita. Pero también se iban introduciendo otras nuevas exigencias para la política educativa: la planificación integral de la educación (en 1968 se celebra el I curso de Planificación Educativa en la Escuela Nacional de Administración Pública); la racionalización de principios jurídicos, económicos, pedagógicos; la incorporación de análisis de costes, de evaluación de resultados o rendimientos, de criterios e indicadores de medida de la eficacia.

Y se hace preciso constatar, también, que si las previsiones y realizaciones de esos planes de desarrollo fueron centrándose, durante una primera fase, en objetivos fundamentalmente cuantitativos (incremento de la escolarización), la LGE se situaba como el inicio de una consideración más cualitativa -pedagógica- de aquellas actuaciones: buscaba extender la oferta, pero además promover la calidad, renovar los procesos pedagógicos, establecer mejoras organizativas y metodológicas que facilitaran la rentabilidad interna del sistema.

Pero, observemos otro hecho. Hay innovaciones en el discurso pedagógico que sostiene la Ley de 1970, aunque podríamos hablar también de que muestra señales de recuperación o vuelta a lo interrumpido y de continuidad; descubrimos con facilidad principios que retoman las aportaciones 
de la Institución Libre de Enseñanza y de la Escuela Nueva, y de la incipiente modernización que llegaría hasta 1939.

Esa atención que la Ley Villar presta a la normatividad científico-técnica contaba con unos precedentes próximos; conocidos, pero que no pueden ser olvidados. Su significación pedagógica tuvo, sin duda, un anticipo y un modelo en los años sesenta, sobre todo durante el ministerio -tal vez poco citado- de Lora Tamayo; en el discurso teórico-técnico y en la normativa legal. Es algo más que curioso constatar una reveladora disposición que, para responder a las incesantes transformaciones socioeconómicas insta a revisar esquemas tradicionales; a ese fin se programa la distribución y realización de las actividades escolares a los efectos de aumentar su eficacia y rendimiento, para conocer el nivel alcanzado por el alumnado en sus estudios en momentos "pedagógica y administrativamente decisivos de su escolaridad». Su artículo $1 .^{\circ}$ estableció el curso como unidad fundamental del trabajo escolar. ${ }^{22}$

Los estudios y propuestas del Centro de Documentación y Orientación Didáctica de la Enseñanza Primaria (CEDODEP) trazan en esos años una clara línea de innovaciones a emprender, que dejan ver la relevancia concedida a la dimensión técnica que debería asumir la política educativa. Se ocupan de las características de la escuela activa, de las necesarias orientaciones para los directores escolares, de la organización y supervisión, de la cuidada distribución del tiempo y trabajo escolar, de la elaboración de programas, de la promoción escolar, de la introducción en las aulas de nuevas tecnologías. Y considero que van trabajando de forma pionera en pro del esfuerzo por definir una actualizada racionalización curricular, por realizar una oportuna evaluación de la eficacia de la enseñanza, y también por el adecuado tratamiento de la diversidad.

Y hay más. En aquel período cobra cierto relieve una mirada pedagógica en la política; se habla de trabajar a favor del máximo rendimiento del profesorado, por el mejoramiento de la organización y rendimiento de la enseñanza, por la incorporación de la promoción escolar en correspondencia con una mejor graduación, por el logro de una enseñanza de mayor calidad; y se regulan organismos como el servicio de Investigación

22 O.M. 22-IV-1963, BOE 29-IV-1963. 
y Experimentación Pedagógica, el Centro de Documentación y Orientación Didáctica de Enseñanza Primaria, el Servicio de Psicología Escolar y Orientación Profesional. ${ }^{23}$

Además, por medio de los nuevos Cuestionarios Nacionales de 1965, se ordenan las materias, actividades y ejercicios, las unidades didácticas, así como los procedimientos de comprobación del trabajo escolar con regulación de niveles, establecimiento de pruebas objetivas, etc. Los cuestionarios ofrecen señales y anticipos respecto a la LGE: hacen referencia a la calidad de la educación, confían en las positivas correlaciones con los avances científicos y psicopedagógicos, apuestan por la educación integral y por el principio de actividad en los métodos, se vinculan explícitamente con el principio de globalización, los centros de interés, el método de proyectos. ${ }^{24}$

En fin, las Bases para una nueva política educativa emiten las señales de todo un ideario pedagógico consecuente y/o coincidente con dichas referencias previas. Y así se califica la educación como un proceso adaptado a la evolución psicobiológica de los educandos; precisando, por lo tanto, la necesaria especialización en función de la diversidad de aptitudes individuales. Allí se asume la consideración de que la enseñanza ha de partir de experiencias significativas, con programas acordes con las exigencias psicopedagógicas del alumnado; y debiendo, además, promover una actividad práctica, innovadora y creativa. La recomendación pedagógica se completa con la insistente llamada a la formación profesional de los enseñantes, a su correcta y continuada preparación en recursos y técnicas didácticas modernas.

Pero tras el capital humano y la corriente de innovación técnica de los sesenta, pasemos a una tercera consideración contextual. Esa mayor demanda de cualificación pedagógica del sistema tuvo otra vinculación. Se va conformando un enfoque cercano a la denominada educación personalizada, que tiene un ámbito y referencia fuera de nuestras fronteras, y que desde concepciones o presupuestos distintos acepta y reitera, sin

\footnotetext{
23 Ley 21-XII-1965, BOE 23-V-1965.

${ }^{24}$ La unidad didáctica, unidad doctrinal, de trabajo y de tiempo, es definida como un grupo de conocimientos y actividades, aprendidos y realizadas en torno a un tema central de gran significación y utilidad para los escolares, lo que facilita la adquisición de nociones o conceptos apropiados a sus capacidades e intereses, y les facilita su contacto con el mundo real.
} 
embargo, principios y prácticas defendidas por la Escuela Nueva. Su acogida aquí resultaba fácil, en la medida en que concordaba con la defensa de la persona y el humanismo integral que mantenían las corrientes educativas espiritualistas y con la nueva pretensión de integrar o conciliar esa posición con el naturalismo pedagógico.

Emmanuel Mounier había presentado la filosofía de una educación personalista, ya en 1936; se basaba en una formación del hombre integral, total, y en un constante y perfectible aprendizaje de la libertad. Su objetivo estaba centrado en el trabajo por despertar seres capaces de vivir y comprometerse como personas, uniendo así su dimensión singular y autónoma con su proyección comunitaria.

Esa centralidad de la persona en la conceptualización de la obra educativa se fue sosteniendo también a través del mensaje de Maritain a los educadores en L'éducation à la croissée des chemins; su discurso les convocaba a respetar las profundidades de la esencia de los niños y niñas, a llamar a su libre voluntad, a prestar cuidadosa atención a su identidad; la educación, para él, es «sacar adelante, es un despertar humano, lo que tiene de humano». En La personne et le bien commun propugnaba una «educación integral para un humanismo integral», estableciendo como fin esencial la conquista -por medio de la inteligencia y de la voluntadde la libertad interior (de autonomía y de realización); y como segundo objetivo proponía preparar para el grupo social, porque entiende que el ser humano no se agota en su propia mismidad sino que se abre desde la libertad a la responsabilidad y la plenitud moral.

Más cercano en el tiempo, el trabajo de Pierre Faure tiene igualmente su influjo aquí y en este aspecto. En 1972 su obra Ideas y métodos en la educación es editada en español, con un prólogo de Ángeles Galino; y más tarde es invitado a difundir su posición a través de la Revista de Educación. Faure define allí algunos puntos esenciales de ese enfoque, caracterizado por el afán puesto en el desarrollo de actitudes, vivencias y actividades, algo que exige al alumnado tomar la iniciativa de su trabajo. Eso es una pedagogía centrada en la personalización del trabajo escolar, con talleres diversificados, programaciones a la medida y una ayuda particularizada. En el mismo número de la revista, Le Gall recalca esa autonomía/participación del alumnado en la definición de su actividad, algo que exige la tarea docente de adaptación y dinamización 
motivadora, y suscita en el alumnado un camino de originalidad, especificidad, iniciativa y responsabilidad. Puntos presentes, como vimos, en la orientación pedagógica de la nueva ley.

Pues bien, cuando comenzaban los años sesenta, García Hoz recogía ya ese término de personalismo en nuestra literatura pedagógica. Le parece asistir entonces a un tiempo de transición pedagógica que puede superar la mera preocupación paidocéntrica, una posición esta que califica como inconsistente, al estar fundada en un indefendible respeto absoluto a la espontaneidad del niño. De tal forma entiende que pueda llegarse a una actitud singular, que él llama personalista: se trata de cuidar y perfeccionar las tendencias espontáneas, solo en cuanto son útiles para suscitar y fortalecer lo personal, todo aquello que convierte a un ser humano en persona.

En el momento de promulgación de la LGE, García Hoz tenía configurada una consideración más completa de la educación personalizada, que se asentará como prácticamente canónica. Educación personalizada, porque el proceso educativo es, al mismo tiempo, un proceso de asimilación cultural y moral (socialización), y de separación individual, de individualización del sujeto como realidad distinta. De manera que esa concepción representa una verdadera integración de procesos de singularidad, de autonomía y de apertura a los otros y a la convivencia; es vía para formar la capacidad de vivir en comunidad, eso sí, de acuerdo con su propio criterio y ejerciendo una responsable libertad. ${ }^{25}$ Términos, también, muy presentes en la Ley Villar.

Y junto a ese descriptor, en la LGE aparece otro territorio temático, el cuarto de los que comentamos. Un concepto clave desde la perspectiva de la relación entre lo social y lo pedagógico: la educación comprensiva, iniciada en los primeros sesenta en diferentes países europeos. Desde esa preocupación importa la ampliación de la oferta escolar, pero también la calidad con equidad. Un largo y difícil recorrido va a apuntarse, al menos, en ese momento; la nueva ley asume la idea de trazar una educación común y general, atender las desigualdades y desventajas, retrasar la diferenciación, contemplar la diversidad, flexibilizar el currículum.

\footnotetext{
${ }_{25}$ Recordemos el trabajo que en esa línea venía realizando Fomento de Centros de Enseñanza, desde 1963, así como las experiencias en el centro de Somosaguas, con Irene Gutiérrez, Tomás Alvira y el propio García Hoz.
} 
Recordemos ejemplos y precedentes. Con Torsten Husén, como hito, el nuevo concepto de igualdad de oportunidades exigía tomar medidas para remover las barreras sociales y económicas, y consecuentemente revisar nociones pedagógicas básicas, ya que la igualdad de oportunidades no significaba tratar a todos los escolares de la misma manera, sino que requería, en ocasiones, un trato desigual para atender de forma justa los arbitrarios efectos determinados por diferencias sociales relevantes; eso, a su vez, demandaba individualización, y estimulaba recursos de compensación y ayuda. En definitiva, reivindicaciones y propuestas que, entre logros y deficiencias o limitaciones, incidían desde hacía años en generar formas de intervención redistributiva y compensatoria sobre la conocida relación entre origen social y éxito escolar, sobre los importantes efectos reproductores y selectivos de la institución escolar. Las políticas educativas de la socialdemocracia sueca habían impulsado aquellas modalidades de intervención sociopedagógica que podían servir como modelo; equality as equality of fair opportunity, definía Rawls en A Theory of Justice.

Son asuntos que la LGE no deja de invocar, aunque de forma muy idealista, escasamente firme y poco crítica. El ejemplo del largo camino francés hacia la comprensividad, sobre todo entre 1963 y 1974, estaba bien próximo. Anteriormente, incluso, el país vecino había ofrecido un documento paradigmático para las ideas y la política pedagógica: el Plan Langevin-Walon, fundamentado en los enfoques sustanciales de la escuela única y la educación nueva, y que postulaba la unificación escolar, el retraso de la diferenciación, y la prolongación de la escolaridad obligatoria (hasta los 18 años) como instrumentos de la democratización escolar. Partía de un principio básico, el de hacer presente la justicia en la escuela, al que debían concurrir dos aspectos complementarios: la igualdad y la diversidad. Igualdad para desarrollar al máximo las capacidades de todos, diversidad para procurar el desarrollo de las diferentes posibilidades de cada escolar según sus aptitudes individuales. ${ }^{26}$

\footnotetext{
${ }^{26}$ El proyecto fue elaborado por/con el espíritu de colaboración del Consejo Nacional de Liberación (entre 1944 y 1947) por una comisión ministerial; finalmente las condiciones políticas provocaron que ni fuera debatido ni publicado por el Ministerio. Plan Langevin-Wallon (Paris: Editions Press Universitaire de France, 1964).
} 
Ahora bien, estas últimas cuestiones nos sugieren otra perspectiva que Husén no dejaba de anotar desde hacía años. ${ }^{27}$ Digámoslo con claridad, la pedagogía ha de tener en cuenta que las reformas educativas no pueden sustituir a las reformas sociales, precisan contar con otros requisitos previos o complementarios. Y en la España de aquellos años de la reforma educativa, subyace y se explicita un cierto regeneracionismo; una posición que recuerda a la consideración orteguiana de la política hecha pedagogía, la pedagogía como la ciencia de transformar las sociedades. Constataremos ahora, y es nuestra quinta consideración sobre contextos y adscripciones, cómo la Ley Villar confiaba mucho en esa proyección; fue un nuevo intento regeneracionista. El profesor Puelles confesó que su estancia por aquellos años en el ministerio le produjo una especie de sentimiento regeneracionista. ${ }^{28}$ Razones, con toda seguridad, había. Veamos.

En 1967, Cotorruelo expresaba algunas consideraciones al respecto, de especial interés y significado para detectar el variopinto y complejo conjunto de creencias e intenciones que integraba la retórica de transformación de ese tiempo: formación, hombres libres, progreso, élite, elección democrática, convivencia, desarrollo económico... y la educación como origen ilustrado de todo lo bueno. ${ }^{29}$

También las Bases de 1969 manifestaron esa preocupación: preparar desde el sistema educativo la que se entiende como previsible sociedad del futuro, más justa, llega a decirse, y con mayor participación en las

\footnotetext{
27 Torsten Husén, Opportunity and Career (Stockholn: Almqvist\&Wiksell, 1959); Talent, equality and meritrocracy (Stockholn: Almqvist\&Wiksell, 1969); Social Background and Educational Career. Research Perpspectives on Equality of Educational Opportunity (Paris: Centre for Educational Research and Innovation (CERI), OECD, 1972). En España publica «Talento, oportunidad y carrera: Un seguimiento de veintiséis años», en Revista de Psicología General y Aplicada 27, n. 119 (1972): 903-926.

${ }_{28}$ Gabriela Ossenbach y José Luis Villalaín, «Entrevista a Manuel de Puelles Benítez», Historia y Memoria de la Educación 1 (2015): 419-460.

${ }^{29}$ Escribe que una política de la educación dirigida a la consecución de una sociedad de hombres libres y responsables, «sólo puede lograrse si toda la población accede a un mínimo de conocimientos; y cabe esperar fundadamente que si esa población ha alcanzado los conocimientos equivalentes al bachiller elemental, las posibilidades de aunar una élite racionalizante, responsable del gobierno de la nación, con un sistema de elección democrática de dicho gobierno, son considerables», p. 21; añadiendo que en una sociedad dinámica «no puede quedar desfasada la formación del hombre sin que se pague un precio muy alto no solo en términos de desarrollo económico, sino también de convivencia política y social, objetivo en sí mismo de la máxima importancia y condición, sine qua non, del progreso social». Agustín Cotorruelo Sendagorta, Educación y Desarrollo (Madrid: Comisaría del Plan de Desarrollo Económico y Social, 1967), 21 y 44, respectivamente.
} 
decisiones políticas. El propio Villar Palasí, con reminiscencias ginerianas, calificaría, al inicio del Libro Blanco, la esperanza en una política educativa dirigida a la reforma integral de la sociedad: construir una educación como revolución, y como forma de hacerla eficaz y profunda.

El Informe Foessa de 1970 detecta, también, ese carácter. En plena época de explosión educativa, señala, la educación se ha transformado en una especie de panacea que va a resolver todos los males; pero ese estudio no omite otra consideración, en este caso sobre la importancia de dos aspectos: «las oportunidades diferenciales para educarse que reciben los miembros de unas u otras clases sociales», y «los propósitos de transformación (o de conservación social) que se persiguen en la extensión de la enseñanza». Sabemos que esas dos posibilidades afectan al sentido y prácticas que propone o adopta la pedagogía. Con todo el informe defiende la anticipación del futuro, de futuros diferentes, refiriéndose a «el porvenir deseable distinto del posible». Y algo bastante curioso: «que la meta del año 2000 está más presente que el telón de 1939 [...] el sentido de 1939 ya no se puede cambiar y la significación del año 2000 está abierta a mil posibilidades». ${ }^{30}$

Y el propio Villar concibe la educación como pilar fundamental para el progreso social, económico y cívico, identificando el problema de España como un problema de educación. Esa era su esperanza en la apertura de las sesiones de la Comisión de Educación: «la revolución pacífica y silente de una reforma educativa que haga esta España nuestra cada vez más grande, cada vez más justa, cada vez más libre». ${ }^{31}$

En el pleno de las Cortes que aprobará la ley, el procurador Jaime Campmany hablará, con el viejo tono regeneracionista, de la falta de educación como causa de postración, de la posibilidad que la nueva ley va a representar para articular nuestra fe colectiva en la enseñanza, y descubrir y aprovechar las fuentes del desarrollo, la libertad y la justicia. ${ }^{32}$ Villar, por su parte, presentó el proyecto como un trascendental

\footnotetext{
${ }^{30}$ Estas frases que el Informe expresa en las páginas 333-339, coinciden con las de Villar Palasí en su intervención en el pleno de las Cortes en 28-VII-1970 (DSCE, 18-28), expresando que el 70\% de los españoles de entonces viviría en la España y el mundo del año 2000.

${ }_{31}$ DSCE, Sesiones de Comisiones, 19 (1-IV-1970), 2-12.

32 Dice Campmany: «un año después del desastre del 98, se preguntaba don Miguel de Unamuno cuál era la raíz de la postración de la enseñanza pública, que es tanto como preguntarse por el origen
} 
reto destinado a «integrar a los españoles desde la base, desde la escuela»; educación, para no repetir los efectos de la incultura en nuestra historia, afirmó. ${ }^{33}$

\section{ARTICULAR Y CANALIZAR PEDAGOGÍA}

Ese espíritu valoraba y hacía presente a la pedagogía en la reforma, como instrumento relevante de transformación social y como recurso imprescindible para el logro de su eficacia educativa. Una aportación que debía construirse desde variados frentes; desde el estudio y la investigación que sustentara el modelo, y desde la difusión y diseminación que activara el protagonismo imprescindible del profesorado. La ley lo expresaba claramente.

Con anterioridad, incluso, se crearon en las universidades los Institutos de Ciencias de la Educación, dirigidos al análisis con métodos científicos de todas las cuestiones que afectaban a la educación misma, tanto en el plano social como en el de los métodos y medios; se confiaba en que podrían convertirse en un instrumento asesor y orientador de la preparación del personal docente, en conexión y al servicio de centros pilotos de innovación e investigación. Igualmente quedaron establecidas las oportunas medidas sobre organización y funciones del Centro Nacional de Investigaciones para el Desarrollo de la Educación, al objeto de coordinar científicamente las tareas de los citados Institutos, difundir y

\footnotetext{
de la postración de un pueblo. Y se respondía con esta formidable acusación: "La base de todo radica en esto: no se cree en la enseñanza” ». Campmany prosigue así: «Hemos necesitado los españoles setenta años (treinta y cinco de fatal desaliento y treinta y cinco de fe regeneradora) para arrancarnos del cuerpo nacional este sambenito infamante, mucho más cruel por ser verdadero, que colgó don Miguel de Unamuno del cuello de aquella España inferior que terminó por despreciar todo cuanto ignoraba y que apenas si se dignaba usar de la cabeza. Hemos necesitado los españoles setenta años para archivar aquel juicio sumarísimo de don Miguel de Unamuno y celebrar este acto de fe colectiva en la enseñanza que hacemos hoy aquí en nombre y representación del pueblo». Enseguida, añade: «Estamos a punto [...] de abrir para España las puertas que dan a los más amplios caminos del desarrollo cultural, económico, social y político. Estamos a punto de abrir para España las puertas de la más ancha grandeza, de la más fina justicia, de la más verdadera libertad. Con esta Ley descubrimos el más rico tesoro, la más impresionante fuente de riquezas que posee España. Y que no es el trigo, ni el mercurio, ni el oro, ni la naranja, ni el petróleo, ni el sol impávido de nuestra serpentina litoral. Es la fuente suprema de las riquezas materiales y espirituales: el hombre. Con esta Ley, el pobre y esquilmado país que fue España descubre la preciosa mina de sus habitantes». DSCE, Diario sesiones del Pleno (28-VII-1970), 18-28.
}

${ }_{33}$ DSCE, Diario sesiones del Pleno (28-VII-1970), 29-35. 
extender los resultados de las mismas, y realizar programas para la renovación del sistema educativo. ${ }^{34}$

Seguramente sería interesante contar con un estudio, detallado e interpretativo, del alcance y resultados de esas acciones, así como de la literatura pedagógica elaborada en los círculos académicos, ${ }^{35}$ y expuesta por medio de publicaciones o de revistas como Bordón, Revista de Educación o Revista Española de Pedagogía.

Pero aquí, dadas las condiciones del artículo, intentaré fijar la atención en un medio que, a mi juicio, representaba una oportunidad para que ese proyecto de innovación llegara a ser conocido, alentado y aplicado en todos los centros escolares; ese no era otro que la revista Vida Escolar, y a ella, entre 1970 y 1976, he acudido para reconocer y sintetizar cómo se fijan posiciones pedagógicas y alientos profesionales, en qué aspectos se ofrecen respuestas concretas sobre técnicas de intervención y recursos metodológicos, y de qué forma se identifican necesidades y problemas, a veces por parte de maestros y maestras. ${ }^{36}$ Innovaciones metodológicas, orientación educativa y cuestiones sobre evaluación, me parece que son, otra vez, referentes fundamentales.

Al considerar la educación preescolar, una especialista destacada, Aurora Medina, afirma que la igualdad de oportunidades no existirá mientras ese nivel no entre en el sistema educativo con categoría propia; e incide en la relevante función formativa de esa etapa, rica y diferente, que debe contribuir al aprovechamiento de lo que es un momento óptimo de aprendizaje (eclosión del lenguaje, conformación de estructuras mentales, psicomotricidad y posesión de esquema corporal) y por lo tanto a la maduración de capacidades, del proceso intelectivo, del

\footnotetext{
${ }^{34}$ Decreto de 24-VII-1969, BOE 15-VIII-1969; O.M. de 28-XI-1969, BOE 10-XII-1969; O.M. de 5 de enero 1971, BOE 21-I-1971.

35 Escribe Escolano que en las secciones de pedagogía se difundía un cuerpo de conocimientos que respondía a «una extraña hibridación epistémica» entre las corrientes neopositivistas y una teoría educativa con sesgo espiritualista y escolástico. Efectivamente, durante largo tiempo perdura la influencia de una corriente sintética que discurre por la vía espiritualista y personalista, que lleva desde Zaragüeta a García Hoz, y tratando de conciliar posiciones e integrar lo filosófico y lo experimental.

${ }^{36}$ Es importante la contribución de profesionales de la Inspección educativa: Aurora Medina de la Fuente, Jacinta García Caselles, Joaquina Gallego, Juan Navarro Higuera, Manuel Rico Vercher, Juan Costa Ribas, Ambrosio Pulpillo, Jaime Acebrón, Alejandro Bañares, José Luis Sánchez Ezcurra, Gonzalo Gómez Dacal, José Martín-Maestro, Antonio González Soler, Carlos Vidal-Box y otros.
} 
desenvolvimiento de la creatividad y la originalidad. Tan fundamental significación le hace demandar que se determinen mejor sus aspectos pedagógicos, organizativos, de profesorado y personal (docente parvulista, auxiliares puericultoras docentes, profesionales médicos y psicológicos, enfermera puericultora, asistente social.

Para ese período se recomiendan los juegos funcionales, configurativos o constructivos, de entrega, simbólicos, y de reglas; los configurativos y simbólicos se consideran como vehículo principal de exploración, de comunicación afectiva y de afán creativo. Siguiendo a Gessel, se valoran sus potencialidades e incidencia en el desarrollo del sector motriz, del lenguaje, del aprendizaje para acomodación-relación con el medio, y para las relaciones sociales (Prieto García-Tuñón).

Y, por otra parte, se postula (García Caselles) el desarrollo de la experiencia mediante la observación de todo el mundo exterior, que ha de hacerse de forma flexible, dinámica y activa; de manera acorde con las enseñanzas de Jean Piaget sobre el desenvolvimiento intelectual del niño; utilizando provechosamente los juegos sensoriales de Decroly.

Tres grandes principios, efectivamente, son propugnados para esta etapa educativa: libertad, que favorece la espontaneidad y promueve capacidad creadora; actividad, realizada a través del juego, dibujo, observación, imaginación, habla; individualización, que orienta la acción de aprendizaje como una experiencia única en cada alumno o alumna (Gallego Jorreto).

Esos principios presidian el trabajo que hace Vida Escolar para diseminar los nuevos enfoques metodológicos. La individualización, frente a la uniformidad, y también la actividad, más allá de la simple instrucción, son defendidas por Arsenio Pacios. Ellas despliegan, a su juicio, las necesidades, los intereses y la adecuada relación de la enseñanza con las propias experiencias de los escolares; produciendo así una enseñanza formativa y más consistente, elevada e integral. Actividad, y creatividad van unidas; Ricardo Marín resalta esa dirección, que abarca «todo aquello en lo que cada cual puede reconocerse a sí mismo, todo lo que sencillamente puede calificarse de original». Ve en ello un nuevo enfoque de la cultura para el cambio y la renovación, y con claro acento futurizante, frente a la rutina, la pasividad y el desinterés; el educador queda convocado, de 
esa forma, a reconocer o descubrir en todos alguna capacidad creadora, a dar oportunidad para su despliegue y realización.

Por eso, y con frecuencia, se insta igualmente a una observación continuada del trabajo de los alumnos; esta queda definida como una nota relevante en la función docente, como una señal auténtica del verdadero profesional de la docencia. Se trata, según Soler Fiérrez, de efectuar una observación de intereses, de dificultades y de logros en cuanto a conocimientos, hábitos y destrezas, de actitudes hacia el aprendizaje; una observación que ha de servir para verificar y redirigir lo realizado.

Siempre en el camino de la individualización Rico Vercher, entre otros, analiza el tema de las fichas de trabajo, alertando sobre su uso y abuso, así como la cautela de comprobar bien su virtualidad. Piensa que no deben desplazar al libro de texto, que no deben conducir a un deterioro en los hábitos de estudio, que no pueden provocar el que no se adquiera una idea de conjunto sobre la temática correspondiente, o que no han de eliminar un tiempo previo (no corto) de estudio personal con material de consulta. ${ }^{37}$

En la revista, además, se manifiesta la importancia del trabajo autónomo, que hay que promover de forma gradual y progresiva, ofreciendo oportunidades de elegir temas, determinar objetivos y organizar las tareas. Es visto como un recurso esencial para individualizar, para adaptar el desarrollo de las actividades educativas al ritmo de trabajo de los alumnos, favoreciendo que adquieran métodos de trabajo eficaz, que conozcan sus posibilidades y puedan autoevaluarse, y el sentido de responsabilidad respecto al mismo. Es un instrumento que facilita dos objetivos: desarrollar la iniciativa y la creatividad, así como preparar para la capacidad de autoaprendizaje (Sánchez Manzano).

También las aportaciones sobre las didácticas específicas tratan de estimular nuevos principios, recursos y procedimientos. Así, la actividad, la observación, la experimentación, la educación científica, son asumidas por esa nueva orientación metodológica. Los ejemplos podrían

\footnotetext{
37 Recordemos que Dottrens, en su obra La enseñanza individualizada (Buenos Aires: Editorial Kapelusz, 1952, 15-20), precisaba el verdadero sentido de esa técnica de trabajo individualizado, no simplemente individual, que debía ser elegido, acomodado y preparado para cada escolar. Por lo tanto, rechazaba un material estandarizado y prefabricado.
} 
multiplicarse. Se propugnan clases de Ciencias Naturales, que han de ser eminentemente activas, que creen situaciones para observar, analizar, clasificar, dibujar, plantear hipótesis, discutir; y conseguir espacios didácticos de investigación y redescubrimiento; y que han de ser profundamente formativos, ya que -como apunta Vidal Box- no solo procuran la adquisición de conocimiento científico, sino que generan disposiciones sustanciales: amor a la verdad, objetividad en el juicio, claridad en el razonamiento, fomento de la crítica.

Y se convoca a una enseñanza de la Física, la Química o la Tecnología que, según escribe Jesús Lahera, ha de basarse en la actualidad, el interés o las experiencias significativas... pero siempre razonando los métodos empleados y discutiendo los resultados obtenidos, realizando y exponiendo síntesis, y sistematizando los conceptos estudiados.

En relación a la didáctica de la Lengua, y por medio de trabajos como los de Álvarez Álvarez, Marín Cabrero o Noriega, la revista sirve de canal para motivar los objetivos y actividades que instan a la cuidadosa programación de la materia -determinación de contenidos y formulación de objetivos operacionales- como proceso coordinador de fines y medios; para poner énfasis en la atención debida a la expresión oral, que mediante ejercicios estimulantes y provocadores ofrezca caminos eficaces para la creatividad y la originalidad, en la función del lenguaje; para insistir en la comprensión lectora, que haga posible la perfecta comprensión de significados, la posibilidad de interpretar ideas, la capacidad real de analizar y sintetizar los textos.

En el significativo ámbito de la educación cívico-social, explicitado con frecuencia como objetivo preferente, la preocupación metodológica también se abre a nuevas perspectivas. Serradilla, por ejemplo, aboga por el conocimiento psicosocial del alumnado por parte de los docentes, por el conocimiento del medio ambiente social o realidad concreta en que viven los escolares y que se constituye como un todo pedagógico y socializador. En su determinación de objetivos a conseguir no faltan algunos que marcan, igualmente, nuevos signos: el ejercicio responsable de la libertad; la adquisición de normas y valores desde la tradición y cultura patrias, pero sin nacionalismos contraproducentes; el fomento del espíritu de compromiso y cooperación internacional; la visión prospectiva de la sociedad, es decir el sentido de cambio y transformación social. Esa 
formación, añade, no ha de ser tanto un espejo de la costumbre social como «faro proyector de criterios, valores y conductas, ignorados o mal practicados en el seno de la sociedad». Algo, sin duda, destacable.

Entremos ahora en otro de los puntos centrales en nuestra sintética exposición: el de la orientación educativa. Un artículo de García Yagüe nos hace ver aspectos esenciales de ese campo, que considera una imprescindible ayuda técnica al objeto de descubrir e intervenir sobre posibilidades y dificultades que acompañan al proceso didáctico. Entiende que, con preparación adecuada y asignación de tiempo de dedicación, el propio profesorado debería intervenir en la tarea de diagnóstico de dificultades, programación de recuperaciones escolares y orientación a las familias; mientras que un personal específico, altamente especializado, y por medio de una red establecida por zonas, tendría a su cargo el desarrollo de programas psicométricos, la elaboración e interpretación de pruebas clínicas, la terapia de conducta, y otras funciones. García Yagüe añade que, en un nivel intermedio entre los dos referentes anteriores, son precisas actividades de diagnóstico y orientación en determinados momentos críticos de la vida escolar (en la incorporación a la EGB, entre los cursos tercero y cuarto, a la entrada en el ciclo superior, y al acabar la escolaridad obligatoria). Y allí mismo aparecen otros apuntes; hace una llamada de alerta contra la excesiva utilización de modelos cuantitativos, denuncia el exagerado empleo de la medición en las ciencias humanas, pide que se evite un lenguaje demasiado técnico en los informes a profesorado y familias. Y otra cosa: encarece a que se preste más dedicación a la esencial orientación y predicción del rendimiento educativo, desde la atención a factores pedagógicos como el dominio de las técnicas de base, el historial académico del escolar, el clima y motivación familiar, la madurez adaptativa y emocional. ${ }^{38}$

La orientación educativa con carácter integral era reclamada por profesionales como Ibáñez Benet o Barberá Albalat, que la entienden como uno de los pilares básicos para todo sistema educativo, implicada

\footnotetext{
38 Años después, García Yagüe, en «Técnicas de la Orientación Escolar en España», Tendencias Pedagógicas 7 (2002): 35-48, insistía en que la orientación escolar no fue aceptada en parte porque invadió la escuela con una euforia exagerada desde mesianismos psicológicos y con modelos psicométricos o patológicos que ayudaban a clasificar o definir sujetos cuando se hacían bien; pero que no podían responder a las exigencias de aprendizaje singularizado ni a la reducción de las conductas inadecuadas o de los fracasos; ni a las necesidades de conocer las circunstancias en que se va a realizar la acción educativa o el aprendizaje.
} 
en el asesoramiento docente, la programación y evaluación, el cumplimiento de las funciones directivas, la resolución de casos de dificultad de aprendizaje o de inadaptación escolar, o el tratamiento de los alumnos de rápido aprendizaje.

Finalmente, en la lectura de Vida Escolar podemos comprobar el interés por el tema de la evaluación. Arsenio Pacios considera que es una tarea complicada, cuya corrección y eficacia hay que atender adecuadamente, priorizando además los aspectos cualitativos de la misma; porque, a su juicio, lo decisivo no es el aparato matemático sino el espíritu de la auténtica evaluación. El catedrático de la Universidad de Madrid reclama la necesaria labor de convencer al profesorado de las ventajas del nuevo sistema, cuya idoneidad para el momento presente da por segura; y es que, escribe, ahora no se trata tanto de seleccionar a los óptimos cuanto de «ayudar a todos a que lleguen hasta donde sus aptitudes se lo permitan».

En ese sentido todo responde al objetivo de un progreso o promoción armónica, de forma continua y permanente, como afirmaba Ambrosio Pulpillo. De esa manera cada uno de los niños o niñas puede avanzar consecutivamente más en una dirección que en otra, al mismo tiempo que ninguna de las facetas fundamentales de su personalidad se quede definitivamente estancada. Hacerlo así, señala Cacharro Pardo, es consecuencia acorde con el principio de personalización; puesto que este exige atender a las diferencias individuales en aptitud, ritmo de trabajo, motivación. Y lógicamente obliga al profesorado a un pronóstico previo de las posibilidades de superación de los alumnos y alumnas, a una observación continuada y sistemática de su conducta, a un seguimiento y análisis de los trabajos y de los progresos. Esa, escribe González Soler, es una ventaja notable de la que servirse, la de proporcionar retroalimentación para que los docentes puedan conocer la situación de su alumnado en un momento determinado y respecto a cierto objetivo; la de ser instrumento, para la mejora del proceso educativo, que permita corregir, reforzar, progresar.

\section{PROBLEMAS, CONTRADICCIONES Y TRANSICIÓN. ENTRE EL PASADO Y EL FUTURO}

Tal vez podamos afirmar que no había mucho de nuevo en la pedagogía de la Ley de 1970, pero sí que se volvía de nuevo a ciertos planteamientos de un ideario que fue interrumpido, furiosamente negado 
durante la dictadura franquista, claramente olvidado, silenciado o desconsiderado en su implementación: vitalizar la educación, adaptarse al desarrollo natural del sujeto del aprendizaje, respetar las necesidades infantiles, interesar a quienes han de aprender, fomentar la actividad personal, pensar en el maestro y la maestra como observadores, generar una disciplina volitiva y activa, permitir una pedagogía diferenciada según ritmos, opciones y especializaciones, una «pedagogía de las águilas que no suben por la escalera», en el decir de Freinet. Ideas y acciones que sí habían existido como proyecto y como práctica: Naturalismo pedagógico, Escuela Nueva; y aquí, entre nosotros, Giner, Cossío, Ferrer... La Escuela Moderna, Revista de Pedagogía. De allí venían las ideas, ahora retomadas, que quisieron promover desde la escuela las profundas energías de la vida, estimular procesos de reestructuración y reorganización de la experiencia, atender la complejidad en los procedimientos didácticos.

En España, las Bases que Luzuriaga propuso, en 1931, para una nueva Ley de Instrucción Pública, ya declaraban con fuerza que la educación era función esencial del Estado, ya defendían el carácter activo y creador que la enseñanza debía asumir. Y reconocían la autonomía de alumnos y alumnas, y exigían una reforma del sistema que estuviera basada en la experimentación de las propuestas, y reclamaban el perfeccionamiento de la formación del magisterio

Más tarde, las tibias tendencias modernizadoras manifestadas por el Ministerio de Ruiz Giménez con los Cuestionarios de 1953, querían ser una directriz técnica adecuada a las exigencias de una pedagogía eficiente. Citaban la necesidad de más actividad, menos memoria, más practicidad. Al introducir los cuestionarios se incorporaba una nueva retórica; o, mejor dicho, se recuperaban palabras e impulsos de una cultura innovadora: «La enseñanza toda será concreta, viva, activa. Participará del ambiente próximo, enlazando con sus realidades». Y precisamente por eso se aclara enseguida que debe huirse de todo verbalismo, de todo memorismo, de toda divagación por los campos alejados de los intereses y afanes del niño. ${ }^{39}$ Podría parecernos que el redactor del texto hubiera leído en La escuela nueva pública de Luzuriaga.

${ }_{39}$ Conviene señalar, además, la clarificadora significación de este texto: «La novedad que supone la existencia de unos cuestionarios nacionales destinados a orientar la labor de nuestras escuelas 
Sí, durante la década de los sesenta hubo también una pedagogía emergente, pero minimizada; se abrió paso una destacable comunidad investigadora, creadora de conocimiento y propuesta psicopedagógica, aunque tuviera escasísima traslación a la escuela real. Pero en ese tiempo, y en 1970, insisto, se omite o enmascara la presencia en la reforma de ciertas influencias innovadoras, que ahora se aceptan y acogen, pero que debían quedar algo invisibilizadas, ya que eran tendencias denunciadas y rechazadas, antes, por las retóricas fundacionales del Régimen. ${ }^{40}$

De modo que la LGE es un buen ejemplo de los procesos de construcción social del sistema educativo, de la constante yuxtaposición y superposición de etapas e influencias, de los puntos de inflexión entre las rupturas, continuidades y discontinuidades sociopedagógicas por las que transita siempre el sistema educativo. En los finales del franquismo confluyen pasado, presente y futuro, conjugados, interactuando, interfiriendo.

Además, la pedagogía que suscribe la reforma, aquella a la que se regresa y a la que se pone como señal para el futuro, quedaría condicionada enseguida por contradicciones, insuficiencias, colisiones, limitaciones e imposibilidades. ${ }^{41}$ Pese al valor pedagógico intrínseco que la

primarias nos ha movido a no introducir en ellos innovaciones que podían haber contribuido a perturbar la marcha de la enseñanza. Ensayos de metodología nueva, tales como las globalizaciones, la concentración de materias afines y los proyectos, que tienen su indicación ya en los primeros pasos de la enseñanza, ya en las tareas experimentales de escuelas de ensayo, solo en muy poca medida son acogidos por los cuestionarios, respetuosos con una tradición escolar que ha convertido a la asignatura en una realidad inesquivable». Y se añade, inmediatamente: «si hemos huido de innovar en exceso, ello no quiere decir que no hayamos procurado atemperar los cuestionarios a los postulados actuales de la ciencia pedagógica. Es posible, incluso, que los de algunas materias parezcan excesivamente revolucionarios, si se tiene en cuenta nuestra tradición escolar». Cuestionarios Nacionales para la Enseñanza Primaria (Madrid: Ministerio de Educación Nacional, 1953): 11.

${ }_{40}$ Resulta curioso que el preámbulo de la ley copiara casi literalmente, en algún caso, expresiones concretas de la exposición de motivos del decreto fundacional del Instituto-Escuela (R.D. de 10-V1918, Gaceta de Madrid, 11-V-1918, pp. 402-404).

${ }^{41}$ Es interesante conocer lo que años después escribe José Blat Gimeno, uno de los artífices de la reforma:«me pidió Diez Hochleitner que preparase el proyecto de Ley General de Educación; le objeté que ello no permitiría tomar en consideración buena parte del material que la consulta estaba deparando y que ello constituiría una contradicción con lo que se había anunciado, además de defraudar los esfuerzos que no pocos organismos y personas habían puesto en la elaboración de sus propuestas en relación con lo propugnado en el Libro Blanco [...]. Traté de indagarlo y se me dio la versión de que se trataba de contrarrestar el escándalo que había producido en la opinión pública el asunto "Matesa", y a ese efecto, se estimaba que tanto el proyecto de Ley Sindical como el de Ley General de Educación interesarían profundamente a la sociedad española y desviarían hacia los mismos la atención popular »; y para justificar su retirada, explica: «Influía en ello mi discrepancia con la tendencia que observaba de orientar la aplicación de la reforma educativa, más con miras al 
norma legal establece, la potencialidad de sus mejores componentes quedaría notoriamente invisibilizada en el debate político, olvidada en su financiación a causa del nulo progreso en la justicia fiscal, ${ }^{42}$ y disminuida por ausencias y/o carencias de la política curricular. Anotemos algunos puntos al respecto.

Recordando, en principio, algo que Popkewitz cuestiona respecto a los discursos de las reformas y su focalización en los aspectos procedimentales, centrados en una visión idealizada y técnica de la ciencia, con independencia de intereses o valores sociales. En efecto, no podemos olvidar lo que conlleva la elección de una concepción tecnocrática, legitimadora del currículum en base a una racionalidad científica y una aplicación técnica que sirven primordialmente para organizar, controlar y garantizar el cumplimiento más eficaz de los objetivos

$\mathrm{Y}$ es necesario advertir las lagunas que se produjeron en la imprescindible comunicación y acercamiento de la reforma al profesorado, fiando en gran parte su materialización al voluntarismo y la autodidaxia. Esto último dejaba una tarea bien difícil a los verdaderos actores y constructores del cambio, sobre quienes pesaba como una losa la tradición de la cultura profesional instalada o la falta de experiencia.

Además de esa obstaculizadora tradición/impericia, otro impedimento fue la falta de previsión y provisión, también de continuidad, en el impulso inicial sostenido entre 1968 y $1972 .{ }^{43}$ La referencia a la pedagogía no podía

efectismo político que a su eficacia técnica y renovadora». Agradezco a Amparo Blat Gimeno el haberme permitido conocer y disfrutar de la lectura de las Memorias inéditas de Don José.

42 En el pleno de Cortes que aprueba la ley, dice Villar: «Para aplicarla en toda su extensión confiamos en que la presión social, que la alienta y la exige, y la propia decisión de estas Cortes, han de conseguir la financiación continuada que nos permita su total implantación y la de toda la reforma. ¿0 es que no sabemos todos, vosotros y yo, qué grupos de presión quisieron negar a esta Ley el pan y la sal del futuro y por qué vericuetos se intentó llegar a ello? La Historia, con mayúscula, lo recogerá. Me basta con decir que sería muy lamentable que un país como el nuestro, en el que la capacidad de consumo de toda suerte de bienes materiales, incluido el lujo, es tan espectacular, no pudiera dar satisfacción por falta de medios a la imperativa demanda social de educación y de cultura». DSCE (28-VII-1970), 33.

${ }^{43}$ La actitud ante el Informe de Villar a la Comisión Educación de las Cortes, en 1972, desvela la crítica o insatisfacción de sus miembros con un gran número de preguntas sobre becas, pago a profesorado interino, problemas de la enseñanza privada, aplicación de la gratuidad, funcionamiento de las juntas provinciales, etc. Son escasas o nula las referencias a cuestiones pedagógicas (DSCE, n. ${ }^{\circ}$ 10 (14-II-1972), 1-80. En 1975 el ministro Martínez Esteruelas manifiesta ser consciente de la deficiencia cualitativa de parte de la escolarización, ante la prioridad que la «urgencia social» imponía en ese campo; al tiempo que señala que el número de unidades subvencionada en el sector no estatal 
reducirse a un elogio o canto, pero en modo esencialista, grandilocuente o estético. Más allá, incluso, de la pertinencia de principios y objetivos, o de la aceptación de un modelo técnico de innovación definido por expertos, se olvidaba -o, ni hubo ocasión de intentarlo- que gran parte de la potencialidad para el cambio reside en el carácter y fuerza de su implementación; por decirlo con la expresión de Fullan: el cambio educativo es «técnicamente simple y socialmente complejo». Si los cambios en el plano didáctico son muy difíciles, «en las creencias son aún más complejos».

Recordemos, además, la decisiva importancia de optar por una estrategia considerada ya entonces como inexcusable. Como Huberman advertía, la mayor parte de las instituciones están orientadas hacia la estabilidad, no disponen de mecanismos para cambiarse a sí mismas. Interesaba, pues, la debida preocupación por las agencias del cambio, por su potencialidad innovadora; y respecto a ello indicaba algunos motores: mayor apoyo financiero, maestros más capacitados, mayor nivel de educación de los padres, buena red de comunicaciones entre los maestros y entre maestros y administradores, elevada congruencia y cohesión la innovación y el medio ambiente real, etc. Estaba clara la necesidad de promover factores que aseguraran cambios duraderos: calidad probada, fácil comunicabilidad, ambiente escolar o institucionalidad más favorable que neutral o refractario, compatibilidad con los valores y las prácticas vigentes, predisposición al cambio en el sistema y la comunidad escolar.

Todo eso debió tenerse en cuenta, claro, atendiendo igualmente a cuestiones como las señaladas por Havelock: la innovación debe producir una alteración significativa que produzca realmente beneficios. Exige, por lo tanto, planificación para ir apoyándola en un buen diagnóstico

ha pasado de 7.215 en 1973 a 19.121 en 1974. En su comparecencia en la Comisión de Educación de las Cortes, las preguntas vuelven a concentrase en temas muy variados como las remuneraciones del profesorado de Educación Física, Formación Política, y Enseñanzas domésticas, las pruebas de acceso a la universidad, el acto de izar la bandera nacional en las escuelas, la inseguridad laboral del profesorado, los focos de subversión aparecidos en las universidades, los problemas de la enseñanza no estatal, etc. Cuando el procurador Galindo Antón (pp. 29-31) le pregunta por el montante presupuestario y los plazos previstos para la ejecución de las obras de construcción escolares declaradas urgentes por la O.M. 24-XI-1973 y D. 8- VIII-1974, el ministro afirma que en esas disposiciones se hace una "constatación de necesidades», y que no se plantean «actos decisorios». DSCE, Comisiones (10-II-1975), 1-98. 
de necesidades; y un adecuado proceso favorecedor de su aceptación y adopción, que genere las aptitudes y conductas requeridas. Nada de eso asumía el modelo y el desarrollo de la ley que analizamos.

Su lógica tecnocrática no se articulaba bien en la red de relaciones socioculturales que conforma lo pedagógico. No asumía algunas perspectivas de las que ha escrito Gimeno Sacristán; sin aprender de los ejemplos del desarrollo sociohistórico de este asunto. Renunciaba a vincularse con una profunda revisión de las teorías de la enseñanza y del aprendizaje, y con una crítica pedagógica de la escuela. Por consiguiente, ese enfoque, dirigido, no tanto a revisar valores y conseguir explicación y cientificidad, como a ofrecer una normatividad eficiente y fundamentada, dejaba sin resolver la problemática de sus posibles inadecuaciones, insuficiencias, o fracasos. Parafraseando a Ardoino, podemos decir que se organizaba una pedagogía del cambio sin animar o generar un cambio de la pedagogía.

Eso supone apreciar lo pedagógico, pero preterir su consecución; hablar de pedagogía como algo al margen de la política y haciendo abstracción del contexto social. En ese aspecto la casuística fue abundante, tras un primer quinquenio en que el desafío de la incidencia real de la reforma quedó frenado con la retirada de Villar, los conflictos políticos y económicos del momento, el recelo de influyentes sectores ante el impulso de lo público, la ausencia de modificaciones fiscales que garantizasen la correspondiente financiación de recursos.

Observemos ciertos puntos sustanciales. En 1972, y durante el V Congreso de Pedagogía, ${ }^{44}$ García Hoz reiteraba una decisiva urgencia: la reforma, auguraba, está condenada al fracaso si nos falta un profesorado eficazmente dispuesto a seguir la línea de la educación renovada. Un informe de 1973 señalaba muchas más cosas. Las políticas de formación en aquel sentido son de máxima urgencia, escribe Castillejo, concluyendo que no podían admitir demora. No basta con entusiasmar al profesorado

\footnotetext{
${ }^{44}$ El Congreso de Pedagogía de 1972 revisó diferentes temas de la reforma cualitativa de la educación, como la formación y perfeccionamiento del personal docente, el personalismo pedagógico o el estímulo de la creatividad (García Garrido, Marín, García Hoz, Rivas Martínez, Benavent, López Herrerías ), así como la orientación escolar (Castillejo, Illueca, Gordillo Álvarez-Valdés), o los aspectos metodológicos (Sanvisens, Quintana, Sarramona, De Urmeneta, Rodríguez Diéguez, De la Orden, Navarro Higueras, Nuria Borrell), y cuestiones concernientes a la evaluación (Illueca, Benavent, Carrasco, Gimeno Sacristán, López Herrerías, Félix Ortega).
} 
afirmaba Rico Vercher, porque sin medios quedaban abocadas a la frustración e inseguridad; mientras que Francisco Cubells cuestiona que unas fichas editadas tengan la suficiente flexibilidad para adaptarlas a cada uno de los alumnos. Costa Ribas sospecha que en las Orientaciones hay un exceso de aspiración si se tiene en cuenta la situación real de nuestros centros y profesorado; y Mariano Yela echa en falta la institucionalización de los servicios de orientación, y la inclusión de una formación básica en orientación en los planes de estudios del profesorado de EGB. Por su parte, Gómez Dacal reconoce funciones básicas en el concepto de evaluación que han sido relegadas a un segundo plano, ya que su complejidad dificulta su aceptación por el profesorado.

En 1976, diferentes participantes en el Congreso de Pedagogía ${ }^{45}$ dan cuenta de la situación. Luis M. Sobrado advierte sobre la necesidad de lograr participación e implicación en la reforma, necesarias para que el cambio educativo se base en la realidad. Gimeno Sacristán señala que, al pretender innovar, no estamos ante una cuestión meramente técnica, porque importan las actitudes que posibiliten cambio, importa contar con las personas que han de vivificar el proyecto, es imprescindible fomentar la capacidad de iniciativa del profesorado.

Precisamente en ese aspecto, De la Rosa presenta un estudio diagnóstico-descriptivo, con una muestra ampliamente significativa, en la que se constata un altísimo porcentaje de desconocimiento de los métodos modernos, o que un 59\% del mismo profesorado considera deficiente, escasa o nula, su preparación en las nuevas técnicas. Y Escolano aboga por la interrelación entre la innovación educativa y el perfeccionamiento docente; ahora bien, matiza, desarrollado no solo con programas convencionales sino con programas que tengan la virtualidad de incardinarse efectivamente, dirigidos al cambio de actitudes y a la motivación para superar inercias y resistencias. Urgía atender a las decisivas dimensiones psicológicas y sociológicas del cambio, aquellas que podían contribuir a la generación de conductas innovadoras.

\footnotetext{
45 VI Congreso Nacional de Pedagogía. Comunicaciones y Ponencias Complementarias (Sociedad Española de Pedagogía): L. Sobrado, «Implicaciones socioinstitucionales en la implantación de modelos de innovación educativa»; Gimeno Sacristán, J., «Bases del cambio metodológico»; B. de la Rosa, «El profesor de EGB ante las modernas exigencias metodológicas educativas»; A. Escolano, «Innovación educativa y perfeccionamiento del profesorado».
} 
En ese sentido las conclusiones del Congreso pedían mejor coordinación entre las directrices político-administrativas y los objetivos y recursos; asimismo que las innovaciones fueran difundidas después de un ajustado contraste de experimentación real; también que los objetivos y los contenidos de la formación docente se orientaran hacia la comprensión e incorporación de las nuevas funciones y competencias requeridas; y demandaban, en fin, el efectivo reconocimiento del papel del orientador en los centros educativos.

Por todo ello considero que la política y la pedagogía de 1970 revelan tres importantes cuestiones: el carácter ahistórico que, como apuntó Goodson, impregna los esfuerzos de reforma del currículum, olvidando su carácter de creación o construcción social; la prevalencia de una pedagogía por objetivos, interesada en lo instrumental y procedimental, impulsora -preferentemente- de programación y tecnología didáctica; y la difícil vertebración de discursos y lenguajes en los procesos de cambio, y de estos con las motivaciones, intereses y recursos de sus agentes, es decir la constante tensión entre los componentes de la cultura escolar. ${ }^{46}$

La propuesta de Villar Palasí introducía en España una orientación en el devenir del cambio curricular, la propia de la década de los sesenta a la que Fullan denominó la de la implementación. En dicho enfoque el significado y la capacidad para el cambio no eran el eje básico, el objeto central; antes que en España aquel impulso había generado ya, simplemente, la adopción de innovación, sin cuestionarse porqués ni la capacidad de los usuarios. Si ese modelo, aún con grandes recursos en otras partes, producía pocos cambios significativos, en nuestro caso sería mucho más inefectivo.

La LGE, eso sí, señaló horizontes y caminos, incorporó y oficializó direcciones y modos que tuvieron, y mantienen aún, no poca persistencia y vigencia. Marcó una vía de modernización con sus clásicas perspectivas de racionalización instrumental, restringida a reformular y restructurar la actividad educativa; y en su nueva llamada a la calidad añadió a nuestro discurso político-legislativo conceptos y retos que se reafirmaron después

\footnotetext{
${ }_{46}$ Más tarde, en el preámbulo de la LOGSE, pudimos leer: «Nuestro propio pasado está repleto de cambios que fueron concebidos con la mejor intención [...] pero que no pudieron enhebrarse con la realidad que pretendían modificar porque, a fuerza de perfilar el modelo ideal perseguido, sólo tomaron en cuenta a esa realidad como rechazo y no como insoslayable punto de partida».
} 
en el preámbulo y articulado de la LOGSE. Ya en el Libro Blanco de 1989 fueron retomados y reconocidos, como objetivos y factores de calidad, asuntos que propugnó la LGE: desarrollo integral de la personalidad, adaptación a las peculiaridades e intereses individuales, metodología activa y participativa, desarrollo de la orientación y tutoría, competencia del profesorado, procedimientos adecuados de evaluación, entre otros. Frente a otras críticas extremas, quiero, en fin, hacer mías las afirmaciones, justas y equilibradas, del profesor Puelles: la LGE fue una ley importante, que tuvo aciertos y errores, que abrió caminos de racionalidad.

Hoy conviene profundizar en lo que realmente sucedió entonces, en sus causas y efectos, e indagar no solo en discursos y datos, sino también en/con la propia memoria y experiencia de sus actores, aprovechando toda su potencialidad informativa, y su capacidad de transmitir vivencias particulares y significativas. Esos testimonios manifestarán implicaciones de la experiencia individual y dimensiones que pertenecen claramente al contexto y la identidad colectiva. Nos ayudarán a interpretar y valorar.

«Es el futuro el que nos lleva al pasado», escribió Hannah Arendt.

\section{Nota sobre el autor}

Alejandro Mayordomo Pérez es catedrático de Teoría e Historia de la Educación en la Universitat de València. Imparte su docencia en la Facultad de Filosofía y Ciencias de la Educación y en la Facultad de Magisterio. A lo largo de su trayectoria académica ha estudiado diversas componentes pedagógicas, sociales y políticas de importante significación en la evolución histórica de la educación española durante los siglos XVIII-XX. Ha sido presidente de la Sociedad Española para el Estudio del Patrimonio Histórico-Educativo, y vicepresidente de la Sociedad Española de Historia de la Educación.

\section{REFERENCIAS}

Álvarez Álvarez, M. ${ }^{a}$ Isabel. «Programación de las actividades lingüísticas», Vida Escolar 135-137 (1972):18-27. 
Ardoino, Jacques. Education et Politique. Propos actuelles sur l'éducation II. Paris: Gauthier-Villars, 1977.

Arendt, Hannah. Entre el pasado y el futuro. Barcelona: Península, 1996.

Barberá Albalat, Vicente. «La orientación del escolar. Principales problemas pedagógicos», Vida Escolar 170-171 (1975): 18-25.

Becker, Gary. Human Capital. Columbia University Press, 1964. Edición en español, El capital humano. Madrid: Alianza, 1983.

Beltrán, Francisco. Politica y reformas curriculares. Valencia: Universitat de València, 1991.

Bousquet, Jacques. «Tendencias del planeamiento educativo en 1968», Revista de Educación 201 (1969): 43-54.

Cacharro Pardo, Francisco. «Evaluación del rendimiento de los escolares», Vida Escolar 145-146 (1973): 19-26.

Castillejo Brull, José Luis. «Funcionalidad normativa y orientadora de los Institutos de Ciencias de la Educación». En Presente y Futuro de la Reforma Educativa. Revisión crítica de la Ley de Educación en el primer trienio de su aplicación. Madrid: Apis, 1973.

Comisión de Evaluación de la Ley General de Educación y Financiamiento de la Reforma Educativa. Informe que eleva al gobierno la Comisión Evaluadora de la Ley General de Educación y Financiamiento de la reforma educativa. Madrid, documento multicopiado, 1976.

Costa Ribas, Juan. «Programación de estudios y actividades en la EGB». Presente y futuro de la Reforma Educativa Revisión crítica de la Ley de Educación en el primer trienio de su aplicación, 181-182. Madrid: Apis, 1973.

Cotorruelo Sendagorta, Agustín. Educación y Desarrollo. Madrid: Comisaria del Plan de Desarrollo Económico y Social, 1967.

Cubells Salas, Francisco. «Organización escolar y equipamiento didáctico de la EGB». En Presente y Futuro de la Reforma Educativa Revisión crítica de la Ley de Educación en el primer trienio de su aplicación, 183-185. Madrid: Apis, 1973.

Cuestionarios Nacionales para la Enseñanza Primaria. Madrid: Ministerio de Educación Nacional, 1953.

Cuestionarios Nacionales de Enseñanza Primaria, Vida Escolar 70-71(1965): 1-96.

De Miguel, Amando y otros. Informe sociológico sobre la situación social de España. Madrid: Fundación Foessa, 1970.

Del Pozo Andrés, M. ${ }^{a}$ del Mar y Braster, J. F. A. «The Reinvention of the New Education Movement in the Franco Dictatorship (Spain, 1936-1976)», Paedagogica Historica 1-2 (2006):109-126.

Díez Hochleitner, Ricardo. Política y Financiación de la Educación. Madrid: Escuela Nacional de Administración Pública, 1967. 
Escolano, Agustín. «Los comienzos de la modernización pedagógica en el franquismo (1951-1964)», Revista Española de Pedagogía 192 (1992): 289-310.

Escolano, Agustín, García Carrasco, Joaquín y Pineda, José María. La investigación pedagógica universitaria en España (1940-1976). Salamanca. Ediciones Universidad-ICE, 1980.

Escolano, Agustín. Historia Ilustrada de la Escuela en España. Madrid: Fundación Germán Sánchez Ruipérez, 2006.

Faure, Pierre. Ideas y métodos en la educación. Madrid: Alianza-UNESCO, 1972.

Faure, Pierre. «La enseñanza personalizada. Origen y evolución», Revista de Educación 247 (1976): 5-10.

Fernández Enguita, Mariano y Henry Levin. «Las reformas comprensivas en Europa y las nuevas formas de desigualdad educativa», Revista de Educación 289 (1989): 49-64.

Fernández Huerta, José. «Tres decenios de innovación didáctico-experimental», Enseñanza. Revista Interuniversitaria de Didáctica 1 (1983): 11-30.

Fullan, Michael. "Overwiew of innovative process and the use», Interchange 3 (1972): 1-46.

Fullan, Michael. Los nuevos significados del cambio en educación. Barcelona: Octaedro, 2002.

Fullan, Michael. «El significado del cambio», Profesorado. Revista de Currículum y Formación del Profesorado 1-2 (2002): 1-14.

Fullan, Michael. Las fuerzas del cambio: la continuación. Madrid: Akal, 2004.

Gallego Jorreto, Joaquina. «Directrices metodológicas», Vida Escolar 135-137 (1972): 85-90.

García Caselles, Jacinta. «La observación de la naturaleza», Vida Escolar 135137, (1972): 44-50.

García Hoz, Víctor. Educación personalizada. Madrid: Instituto de Pedagogía del CSIC, 1970.

García Hoz, Víctor. Cuestiones de Filosofía de la Educación. Madrid: Rialp, 1962.

García Yagüe, Juan. «La orientación escolar como aventura pedagógica: antecedentes y problemas», Vida Escolar 183-184 (1976): 9-14.

Gimeno Sacristán, José. Teoría de la enseñanza y desarrollo del currículo. Madrid: Anaya,1988.

Gómez Dacal, Gonzalo. «Problemática de la evaluación continua». En Presente y Futuro de la Reforma Educativa. Revisión crítica de la Ley de Educación en el primer trienio de su aplicación, 149-151. Madrid: Apis, 1973.

Goodson, Ivor, Historia del curriculum. Barcelona: Pomares-Corredor, 1995.

Havelock, Ronald. Guide to innovation in education. Ann Arbor, University of Michigan, 1970.

Havelock, Ronald. Guide for innovation through dissemination and utilization of knowledge. Ann Arbor, University of Michigan, 1971. 
Havelock, Ronald. The change agent's guide to innovation in education. Englewoods, New Jersey: Educational Technology Publications, 1973.

Huberman, A. Michael. Cómo se realizan los cambios en la educación: una contribución al estudio de la innovación. Paris: UNESCO, 1973.

Ibáñez Benet, Rafael. «El Servicio de Orientación en los centros de EGB», Vida Escolar 183-184 (1976): 125-127.

Informe del Banco Internacional de Reconstrucción y Fomento. El desarrollo económico de España. Madrid: Oficina de Coordinación y Programación Económica, 1962.

Informe que eleva al Gobierno la comisión evaluadora de la Ley General de Educación y Financiamiento de la Reforma Educativa en cumplimiento del decreto 186/76 de 6 de febrero Madrid: Ministerio de Educación y Ciencia, 1975.

La educación en España. Bases para una política educativa. Madrid: Ministerio de Educación y Ciencia, 1969.

La planificación de la educación para el desarrollo económico y social. Paris: Proyecto Regional Mediterráneo, OCDE 1967.

Lahera Claramonte, J. «Enseñanza de la Física, la Química y la Tecnología en la EGB», Vida Escolar 145-146 (1973): 13-18.

Las necesidades de educación y desarrollo económico-social de España. Madrid: Proyecto Regional Mediterráneo, OCDE-Ministerio de Educación Nacional, 1963.

Lázaro, Luis Miguel, Martínez, Angels y Mayordomo, Alejandro. «Perspectiva histórica de la innovación educativa en España, 1970-2008». En Estudios sobre la innovación educativa en España, 59-334. Madrid: Ministerio de Educación, 2011.

Le Gall, Monique. «¿Por qué y cómo una pedagogía personalista? De los objetivos a las Técnicas», Revista de Educación 247 (1976): 11-20.

Marín Cabrero, Rosa. «La expresión oral en EGB», Vida Escolar 139-140 (1972): 33-38.

Marín Ibáñez, Ricardo. Principios de la educación contemporánea. Madrid: Rialp, 1972.

Maritain, Jacques. L'éducation à la croissé des chemins. Paris: Librairie Universelle de France, 1947. En español, La educación en este momento crucial, Buenos Aires: Desclée de Brouwer, 1966.

Maritain, Jacques. La personne et le bien commun. Paris: Desclée de Brouwer 1947. En español, La persona y el bien común. Buenos Aires: Club de Lectores, 1968.

Mayordomo, Alejandro. Estudios sobre la política educativa durante el franquismo. Universitat de Valencia, 1999.

Mayordomo, Alejandro. «El legado de las voces y los escritos: su valor como testimonio de la cultura escolar», Revista Iberoamericana del Patrimonio Histórico-Educativo 6 (2020): 1-31. 
Medina, Aurora. «La educación pre-escolar en la nueva ley», Vida Escolar 135137, (1972): 4-10.

Ministerio de Educación y Ciencia. La educación en España. Bases para una politica educativa. Madrid: Secretaría General Técnica, 1970.

Mounier, Emmanuel. «Manifest au service du personnalisme». En Ouvres, vol I. Paris: Editions du Seuil, 1966.

Noriega, Juan. "Comprensión lectora e interpretación de textos», Vida Escolar 139-140 (1972): 48-54.

Ossenbach, Gabriela y José Luis Villalaín. «Entrevista a Manuel de Puelles Benítez», Historia y Memoria de la Educación 1 (2015):419-460.

Pacios, Arsenio. «Exigencias metodológicas de la nueva orientación educativa», Vida Escolar 127 (1971): 5-10.

Pacios, Arsenio. «El control de los resultados de la evaluación», Vida Escolar 149-150 (1973): 5-12.

Pineda Arroyo, José M. '. La literatura pedagógica española contemporánea (19421976). Salamanca: Universidad de Salamanca, 1987.

Popkewitz, Thomas S. «Política, conocimiento y poder: algunas cuestiones para el estudio de las reformas educativas», Revista de Educación 305 (1994): 103-137.

Popkewitz, Thomas S. Sociología politica de las reformas educativas. Madrid-La Coruña: Morata-Fundación Paideia, 1994.

Pozo Andrés, M. ${ }^{a}$ del Mar y Rabazas Romero, Teresa. "Políticas educativas y prácticas escolares: la aplicación de la Ley de Enseñanza Primaria de 1945 en las aulas», Bordón: Revista de Pedagogía 65, n. 4 (2013): 119-133.

Prieto García-Tuñón, M. ${ }^{a}$ Asunción. «El juego en el nivel pre-escolar», Vida Escolar 135-137 (1972): 23-30.

Projet Régional Méditerraneen, Espagne. París: OCDE, 1968.

Puelles, Manuel de. Educación e ideología en la España contemporánea. Barcelona: Labor, 1980.

Pulpillo, A. «La promoción o progreso continuo del alumno», Vida Escolar 138 (1972): 37-41.

Rabazas Romero, Teresa, Carlos Sanz Simón y Sara Ramos Zamora. «La renovación pedagógica de la Institución Teresiana en el franquismo», Revista de Educación 388 (2020): 109-132.

Rico Vercher, Manuel. «El control de calidad del sistema educativo». En Presente y Futuro de la Reforma Educativa Revisión crítica de la Ley de Educación en el primer trienio de su aplicación, 70-72. Madrid: Apis, 1973.

Rico Vercher, Manuel. «Técnicas de empleo de las fichas escolares», Vida Escolar 165-166 (1975): 18-23.

Ruiz Berrio, Julio, Teresa Rabazas y Sara Ramos. «The reception of the New Education in Spain by means of manuals on the History of Education for 
teacher training colleges (1898-1976)», Paedagogica Historica 42 (2006): 127-141.

Ruiz Gutiérrez, Irene. Experiencia Somosaguas. Un sistema de educación personalizada. Madrid: Narcea, 1970.

Sánchez Manzano, Orencio. «El trabajo autónomo de los alumnos», Vida Escolar 175-176 (1976): 4-5.

Sarason, Seymour B. The culture of the school and the problem of change. Boston: Allyn \& Bacon, 1971.

Schultz, Theodore. «Education and economic growth». En Social Forces Influencing American Education. Chicago: National Society for the Study of Education, 1961.

Schultz, Theodore, "Investment in Human Capital», The American Economic Review 1 (1961): 1-17.

Serradilla Calvo, Martín. «Principios metodológicos de la educación cívico-social», Vida Escolar 141-142 (1972):13-19.

Soler Fiérrez, Eduardo. «La observación diaria del trabajo del alumno». Vida Escolar 145-146 (1973): 28-34.

Vidal Box, Carlos. «La enseñanza de las Ciencias Naturales en el segundo ciclo de la EGB», Vida Escolar 131-132 (1971): 12-21.

Yela Granizo, Mariano. «Institucionalización de los Servicios de Orientación Escolar». En Presente y Futuro de la Reforma Educativa. Revisión crítica de la Ley de Educación en el primer trienio de su aplicación, 165-167. Madrid: Apis, 1973. 